\title{
Eksplorasi Kebutuhan Bahan Ajar pada Matakuliah Bioprospeksi
}

\author{
Nelda Anasthasia Serena ${ }^{1}$, Endang Suarsini ${ }^{1}$, Betty Lukiati ${ }^{1}$ \\ ${ }^{1}$ Pendidikan Biologi-Universitas Negeri Malang
}

\begin{tabular}{l} 
INFO ARTIKEL \\
\hline Riwayat Artikel: \\
Diterima: $15-11-2019$ \\
Disetujui: $18-05-2020$
\end{tabular}

\section{Kata kunci:}

teaching materials bioprospection; problem based learning; bahan ajar; bioprospeksi; problem based learning

\author{
Alamat Korespondensi: \\ Nelda Anasthasia Serena \\ Pendidikan Biologi \\ Universitas Negeri Malang \\ Jalan Semarang 5 Malang \\ E-mail: neldanasthasiaserena@gmail.com
}

\begin{abstract}
ABSTRAK
Abstract: This study aims to determine the necessity of teaching materials in Bioprospection subject. This type of descriptive qualitative research with observation, questionnaire and test data collection techniques. Necessity analysis results $92 \%$ students had difficulty understanding Bioprospect material because the concept is difficult to apply (48\%), complex material (24\%), lack of teaching materials (20\%). Students need teaching materials that are flexible, easy to understand, reliable, practical, and easy access. Preliminary test show cognitive learning outcomes score is 52, 4 (low) and critical thinking skills score is $48.2 \%$ (low). The conclusion is needed a module by research based on Problem-Based Learning that can improve critical thinking and cognitive learning outcomes of students in the Bioprospection subject.
\end{abstract}

\begin{abstract}
Abstrak: Penelitian ini bertujuan mengetahui kebutuhan bahan ajar pada matakuliah Bioprospeksi. Jenis penelitian deskriptif kualitatif dengan teknik pengambilan data observasi, angket, dan tes. Hasil analisis kebutuhan 92\% mahasiswa kesulitan memahami Bioprospeksi karena sulit mengaplikasikan konsep (48\%), materi kompleks (24\%), kurangnya bahan ajar (20\%). Mahasiswa membutuhkan bahan ajar yang fleksibel, mudah dipahami, terpercaya, praktis, dan akses informasinya mudah. Hasil tes awal menunjukkan hasil belajar kognitif dengan rerata 52, 4 (rendah) dan keterampilan berpikir kritis mahasiswa sebesar 48,2\% (rendah). Simpulan penelitian dibutuhkan modul Problem Based Learning berdasarkan hasil penelitian untuk meningkatkan keterampilan berpikir kritis dan hasil belajar kognitif mahasiswa pada matakuliah Bioprospeksi.
\end{abstract}

Pendidikan tinggi sebagai bagian dari usaha untuk meningkatkan taraf kesejahteraan kehidupan manusia adalah usaha sadar dan terencana untuk mewujudkan suasana belajar dan proses pembelajaran agar peserta didik secara aktif mengembangkan potensi dirinya (Kementerian Pendidikan dan Kebudayaan, 2012). Pemerintah Indonesia merancang Kerangka Kualifikasi Nasional Indonesia (KKNI) yang memiliki sembilan level kualifikasi, lulusan strata 1 (S1) termasuk ke dalam level enam KKNI dituntut agar mampu menerapkan pemikiran logis, kritis, inovatif, bermutu, dan terukur pada bidang keahliannya sesuai dengan standar kompetensi kerja bidang yang bersangkutan (Direktorat Jenderal Pendidikan Tinggi, 2014). Hal ini menyebabkan dosen harus dapat merancang pembelajaran yang baik agar lulusan S1 yang dihasilkan sesuai dengan tuntutan KKNI.

Upaya yang dapat dilakukan untuk memenuhi tuntutan KKNI pada jenjang S1 adalah dengan membuat pembelajaran yang kontekstual. Pembelajaran yang kontekstual diperlukan pada matakuliah Bioprospeksi Program Studi Biologi Universitas Islam Malang. Tuntutan pada matakuliah Bioprospeksi yaitu mahasiswa diharapkan mampu menguasai konsep teoritis dan dapat menganalisis masalah serta memberikan solusi berdasarkan ruang lingkup cakupan bioprospeksi (Sjakoer, 2019). Mahasiswa perlu mengembangkan keterampilan abad 21 agar dapat memenuhi tuntutan matakuliah Bioprospeksi.

Pendidikan abad 21 adalah pendidikan yang berhubungan dengan keterampilan, pengetahuan, kecakapan, sikap, dan menguasai teknologi informasi dan teknologi (Greenhill \& Petroff, 2010). Keterampilan abad 21 adalah keterampilan yang dibutuhkan mahasiswa untuk berhasil dalam berkarier di abad ini. Orientasi pendidikan dewasa ini tentang persiapan mahasiswa untuk dapat memiliki keterampilan berpikir. Keterampilan berpikir ini dikenal juga dengan sebutan $4 C$ 's yaitu critical thinking (berpikir kritis) dan problem solving (memecahkan masalah), communication (berkomunikasi), collaboration (bgerkolaborasi), serta creativity (kreativitas) dan innovation (berinovasi) (Gates et al., 2012). Keterampilan berpikir dapat membantu memenuhi capaian pembelajaran matakuliah Bioprospeksi. 
Keterampilan berpikir dapat dipelajari melalui proses pembelajaran mandiri (Kopzhassarova, Akbayeva, Eskazinova, Belgibayeva, \& Tazhikeyeva, 2016). Mahasiswa diharapkan mampu menjadi orang yang berpikir analitis, dapat memecahkan berbagai masalah di kehidupan sehari-hari, dan menjadi pribadi yang bertanggung jawab. Keterampilan menganalisis, menginterpretasikan, ketepatan dalam pemecahan masalah, dan penalaran lebih penting daripada pengetahuan itu sendiri dalam menentukan keberhasilan seseorang dalam menjalani program kuliah (Conley, 2007). Pembelajaran matakuliah Biorospeksi memerlukan sumber belajar yang dapat menunjang keterampilan abad 21 untuk dapat membantu memenuhi capaian pembelajaran.

Sumber belajar dapat didefinisikan sebagai instrumen presentasi dan transmisi materi pendidikan yang telah ditentukan, baik secara terpisah maupun dalam bentuk gabungan sebagai kepentingan kegiatan pembelajaran (Bušljeta, 2013). Sumber belajar dapat meningkatkan efektivitas serta efisiensi pembelajaran, mudah digunakan dan menyenangkan untuk kelangsungan pembelajaran (Supriadi, 2015). Sumber belajar diharapkan dapat membantu mahasiswa memahami materi Bioprospeksi di berbagai bidang kehidupan. Sumber belajar yang baik dapat membantu memenuhi capaian pembelajaran matakuliah (Hamid \& Jailani, 2016). Salah satu sumber belajar yang dapat digunakan mahasiswa dan dosen untuk menunjang keterampilan abad 21 adalah bahan ajar dengan materi yang kontekstual berdasarkan hasil penelitian (Persada, 2017; Sarah, Iskandar, \& Andriyani, 2019). Tujuan penelitian adalah untuk mengetahui kebutuhan bahan ajar pada matakuliah Bioprospeksi yang dapat menunjang keterampilan abad 21 mahasiswa UNISMA.

\section{METODE}

Jenis penelitian ini adalah deskriptif kualitatif. Penelitian dilakukan di Universitas Islam Malang pada program studi S1 Biologi di matakuliah Bioprospeksi. Penentuan sampel dilakukan dengan purposive random sampling dengan 37 mahasiswa sebagai sampel. Penelitian dilakukan pada bulan Februari-Maret tahun 2019. Teknik pengambilan data dengan menggunakan observasi kelas, soal tes awal keterampilan berpikir kritis dan hasil belajar, serta angket kebutuhan bahan ajar mahasiswa dan dosen. Penelitian ini dilakukan berdasarkan tahap analisis (Analyze) pada model pengembangan ADDIE yaitu analisis kurikulum, analisis pembelajaran, analisis materi, dan analisis kebutuhan bahan ajar.

\section{HASIL}

Observasi pembelajaran matakuliah Bioprospeksi dilakukan untuk mengetahui keadaan kelas yang sebenarnya tanpa ada usaha untuk memengaruhi kondisi kelas yang sedang diamati. Peneliti sebagai pengamat ikut serta dalam proses pembelajaran matakuliah Bioprospeksi. Hasil observasi pada kegiatan perkuliahan Bioprospeksi di UNISMA disajikan pada tabel 1 .

Tabel 1. Hasil Observasi Perkuliahan Bioprospeksi

\begin{tabular}{|c|c|c|c|}
\hline No. & Aspek yang diamati & Hasil Observasi & $\begin{array}{ll} & \text { Keterangan } \\
\end{array}$ \\
\hline 1. & $\begin{array}{l}\text { Metode } \\
\text { pembelajaran }\end{array}$ & $\begin{array}{l}\text { Presentasi, diskusi, } \\
\text { dan ceramah }\end{array}$ & $\begin{array}{l}\text { Presentasi dilakukan secara berkelompok lalu melakukan tanya-jawab sebagai bentuk } \\
\text { diskusi antara penyaji dengan teman sekelas. Dosen memberikan penguatan pada } \\
\text { akhir diskusi. }\end{array}$ \\
\hline 2. & Media pembelajaran & $\begin{array}{l}\text { Artikel jurnal dan } e- \\
\text { book }\end{array}$ & $\begin{array}{l}\text { Perkuliahan dilakukan dengan mengulas artikel jurnal yang berhubungan dengan } \\
\text { materi Bioprospeksi dan mengambil referensi dari e-book. }\end{array}$ \\
\hline 3. & Motivasi mahasiswa & Masih rendah & $\begin{array}{l}\text { Mahasiswa yang mengajukan pertanyaan hanya beberapa orang saja. Mahasiswa lain } \\
\text { terlihat pasif dan tidak fokus dalam belajar. }\end{array}$ \\
\hline 4. & Model pembelajaran & $\begin{array}{l}\text { Research Based } \\
\text { Learning }\end{array}$ & $\begin{array}{l}\text { Penggunaan model pembelajaran kurang maksimal karena mahasiswa hanya } \\
\text { mengulas kembali penelitian terdahulu. }\end{array}$ \\
\hline 5. & Level Kognitif & $\begin{array}{l}\text { Masih pada level } \\
\text { kognitif } \mathrm{C} 2 \text { yaitu } \\
\text { memahami }\end{array}$ & $\begin{array}{l}\text { Pertanyaan yang diajukan mahasiswa masih berupa } \mathrm{C} 2 \text {. Masih jarang yang } \\
\text { mengajukan pertanyaan berupa } \mathrm{C} 3 \text { dan } \mathrm{C} 4 \text {. }\end{array}$ \\
\hline
\end{tabular}

Tabel 1 menunjukkan hasil observasi yang dilakukan pada proses pembelajaran matakuliah Bioprospeksi bahwa pembelajaran menggunakan presentasi, diskusi, dan ceramah. Berdasarkan hasil observasi, mahasiswa belum aktif untuk mengeksplorasi, mahasiswa masih kurang dirangsang untuk berpikir kritis, dan keterampilan mahasiswa untuk memecahkan masalah masih kurang. Pembelajaran harus dapat mendukung mahasiswa dalam mencapai hasil belajar kognitif yang baik dan mengembangkan keterampilan berpikir kritis mahasiswa dengan metode pembelajaran yang sesuai. Model pembelajaran research based learning yang digunakan pada matakuliah Biopropeksi kurang maksimal. Metode pembelajaran yang digunakan belum dapat membuat mahasiswa termotivasi untuk belajar. Media pembelajaran yang digunakan pada matakuliah Bioprospeksi hanya artikel jurnal dan $e$-book.

Analisis kebutuhan dilakukan pada tanggal 28 Maret 2019 di UNISMA. Analisis kebutuhan dilakukan terhadap dosen pengampu matakuliah Bioprospeki dan mahasiswa yang mengikuti matakuliah tersebut dengan pemberian angket. Hasil analisis kebutuhan dosen dan mahasiswa pada matakuliah Bioprospeksi disajikan pada tabel 2. 
Tabel 2. Hasil Angket Analisis Kebutuhan Dosen dan Mahasiswa

\begin{tabular}{|c|c|c|c|}
\hline No. & Aspek yang dianalisis & Hasil & Keterangan \\
\hline 1 & Kurikulum & $\begin{array}{l}\text { Rencana Perkuliahan Semester (RPS) yang memuat Capaian Pembelajaran } \\
\text { (CP), Capaian Pembelajaran Mata Kuliah (CPMK), dan Sub CPMK telah } \\
\text { memenuhi tuntutan KKNI }\end{array}$ & \\
\hline 2 & Materi Perkuliahan & $\begin{array}{l}\text { Materi yang disampaikan sesuai dengan hasil penelitian yang berkaitan } \\
\text { dengan Bioprospeksi } \\
\text { Materi dibahas secara berkelompok oleh mahasiswa berdasarkan diskusi di } \\
\text { kelas } \\
\text { Belum dibahas konsep pembuatan bioetanol sebagai energi terbarukan pada } \\
\text { materi Bioteknologi }\end{array}$ & \\
\hline 3 & Sumber Belajar Perkuliahan & $\begin{array}{l}\text { Artikel jurnal, e-book, dan handout. } \\
\text { Artikel yang disampaikan sebagian besar berasal dari informasi dosen. }\end{array}$ & \\
\hline 4 & $\begin{array}{l}\text { Pemahaman mahasiswa pada materi } \\
\text { Bioprospeksi }\end{array}$ & $\begin{array}{l}\text { Sulit (materi abstrak 24\%, aplikasi konsep susah } 48 \% \text {, kurangnya sumber } \\
\text { belajar } 20 \% \text { ) } \\
\text { Mudah (artikel jurnal terkait Bioprospeksi mudah ditemukan lewat internet) }\end{array}$ & $\begin{array}{l}92 \% \\
8 \% \\
\end{array}$ \\
\hline 5 & $\begin{array}{l}\text { Aplikasi bidang Bioprospeksi yang } \\
\text { dipahami mahasiswa }\end{array}$ & $\begin{array}{l}\text { Pangan } \\
\text { Kesehatan } \\
\text { Pertanian } \\
\text { Kosmetik } \\
\text { Biomaterial } \\
\text { Energi } \\
\text { Kelautan } \\
\text { Lainnya }\end{array}$ & $\begin{array}{l}25 \% \\
28 \% \\
9 \% \\
6 \% \\
9 \% \\
10 \% \\
7 \% \\
6 \%\end{array}$ \\
\hline 6 & $\begin{array}{l}\text { Sumber belajar yang sering digunakan } \\
\text { mahasiswa dalam pembelajaran } \\
\text { Bioprospeksi }\end{array}$ & $\begin{array}{l}\text { internet } \\
e \text {-book } \\
\text { petunjuk praktikum } \\
\text { buku ajar }\end{array}$ & $\begin{array}{l}31 \% \\
23 \% \\
15 \% \\
11 \%\end{array}$ \\
\hline 7 & Bahan ajar yang dibutuhkan mahasiswa & $\begin{array}{l}\text { fleksibel, mudah dipahami, sumbernya terpercaya, praktis, dan akses } \\
\text { informasinya mudah }\end{array}$ & \\
\hline 8 & Cara belajar yang diinginkan mahasiswa & $\begin{array}{l}\text { Praktikum lapangan } \\
\text { Berbasis penelitian } \\
\text { Presentasi diskusi } \\
\text { Lainnya }\end{array}$ & $\begin{array}{l}32 \% \\
26 \% \\
20 \% \\
22 \%\end{array}$ \\
\hline 9 & $\begin{array}{l}\text { Situasi Belajar yang diinginkan } \\
\text { Mahasiswa }\end{array}$ & $\begin{array}{l}\text { Individu } \\
\text { Kelompok }\end{array}$ & $\begin{array}{c}8 \% \\
92 \%\end{array}$ \\
\hline
\end{tabular}

Berdasarkan tabel 2, mahasiswa lebih memahami materi bioprospeksi pada bidang pangan (25\%) dan kesehatan (28\%). Hanya $10 \%$ mahasiswa yang telah menempuh Bioprospeksi yang memahami aplikasi Bioprospeksi pada bidang energi. Hal ini karena mahasiswa masih kekurangan sumber belajar bioprospeksi yang berkaitan dengan bidang energi. Hasil angket dengan dosen pengampu matakuliah Bioprospeksi menunjukkan adanya kendala pada saat mengajar matakuliah Bioprospeksi yaitu kurangnya materi bidang energi dan praktikum yang berkaitan dengan teknologi. Dosen pengampu mengaku perlu adanya perbaikan dan peningkatan sumber belajar bioprospeksi pada materi teknologi. Dosen pengampu matakuliah setuju untuk dikembangkan suatu bahan ajar tentang energi terbarukan yaitu bioetanol.

Tabel 2 menunjukkan bahwa 92\% mahasiswa masih mengalami kesulitan dalam memahami materi Bioprospeksi. Berdasarkan hasil angket analisis kebutuhan mahasiswa menyatakan masih sulit mengaplikasikan konsep di kehidupan seharihari sebanyak $48 \%$, sebanyak $24 \%$ mahasiswa menyatakan kesulitan karena materi yang abstrak dan kompleks, $20 \%$ mahasiswa menyatakan kesulitan karena kurangnya ketersediaan bahan ajar yang relevan serta mudah diaplikasikan dalam kehidupan sehari-hari, dan sebagian mahasiswa menyatakan susahnya akses ke bahan ajar yang relevan dengan matakuliah Bioprospeksi. Berdasarkan hasil analisis tentang sumber belajar didapatkan bahwa mahasiswa bioprospeksi lebih banyak menggunakan internet yaitu $31 \%, 23 \%$ dari $e$-book, $15 \%$ dari petunjuk praktikum, dan $11 \%$ dari buku ajar. Tes awal mahasiswa dilakukan untuk mengetahui kemampuan awal mahasiswa dalam aspek keterampilan berpikir kritis dan hasil belajar kognitif. Hasil tes awal mahasiswa UNISMA disajikan pada tabel 3.

Tabel 3. Hasil Tes Awal Mahasiswa

\begin{tabular}{clll}
\hline No. & Aspek yang diukur & Hasil Tes Awal & Keterangan \\
\hline 1 & Keterampilan Berpikir Kritis & Rendah & $48,2 \%$ \\
2 & Hasil Belajar Kognitif & Rendah & 52,4 \\
\hline
\end{tabular}


Tabel 3 menunjukkan hasil tes awal dari mahasiswa UNISMA yang sedang menempuh matakuliah Bioprospeksi menunjukkan bahwa hasil belajar kognitif masih rendah yaitu dengan rerata 52,4 dan keterampilan berpikir kritis masih tergolong rendah dengan rerata seluruh aspek sebesar $48,2 \%$.

\section{PEMBAHASAN}

Berdasarkan hasil observasi, metode pembelajaran yang digunakan pada pembelajaran matakuliah Bioprospeksi belum dapat membuat mahasiswa termotivasi untuk belajar. Motivasi belajar mahasiswa sangat penting dalam menentukan hasil akhir pembelajaran. Hal ini karena motivasi belajar adalah dapat mendorong mahasiswa untuk mencapai tujuan pembelajaran yang telah ditentukan (Masni, 2015). Metode pembelajaran yang digunakan untuk memotivasi mahasiswa belajar harus bervariasi (Embo, 2017), menyenangkan (Nasution, 2017), dan dibantu dengan media pembelajaran yang baik (Khasanah, 2014).

Pembelajaran Bioprospeksi menggunakan media pembelajaran berupa artikel jurnal dan e-book. Mahasiswa mencari berbagai macam artikel jurnal dan $e$-book yang berkaitan dengan materi yang dipelajari, lalu mempresentasikannya di depan kelas. Pembelajaran akan lebih baik jika menggunakan media yang berkaitan langsung dengan kehidupan mahasiswa (Nugraheni, 2012; Wijoyo, 2018). Mahasiswa dapat mencari masalah yang berkaitan dengan Bioprospeksi di sekitar lingkungannya yang dapat dijadikan bahan diskusi. Mahasiswa juga dapat melakukan praktikum agar mahasiswa dapat belajar melalui pengalamannya sendiri. Mahasiswa juga dapat melakukan penelitian tentang materi yang diajarkan pada matakuliah Bioprospeksi, hal ini dapat dilakukan dengan model pembelajaran yang menunjang pembelajaran tersebut.

Model pembelajaran research based learning yang digunakan pada matakuliah Biopropeksi kurang maksimal. Hal ini karena mahasiswa melakukan analisis artikel jurnal terkait materi biopropeksi, namun tanpa melakukan kegiatan penelitian (research) itu sendiri. Model pembelajaran research based learning melibatkan penelitian kolaboratif interdisipliner yang dilakukan mahasiswa dalam pembelajaran, yang berarti bahwa ada hubungan antara pengalaman belajar mereka di kelas dan penemuan baru dalam melakukan penelitian (Rosenshine, 2012). Model pembelajaran research based learning jika digunakan secara maksimal dapat mengembangkan kemampuan kognitif mahasiswa (Susiani, Salimi, \& Hidayah, 2018).

Kemampuan kognitif adalah potensi intelektual yang memaksimalkan kemampuan berpikir, kemampuan ini diperlukan untuk melakukan kegiatan dari yang paling sederhana hingga yang paling kompleks (Basri, 2018). Kemampuan kognitif berhubungan dengan mekanisme bagaimana kita belajar, mengingat, memecahkan masalah, dan memperhatikan kejadian di sekitar kita (Novita \& Afifah, 2014). Kemampuan kognitif dari yang terendah (C1) sampai yang paling tinggi (C6) adalah remembering (mengingat), understanding (memahami), applying (mengaplikasikan), analyzing (menganalisis), evaluating (mengevaluasi) dan creating (menciptakan) (Anderson \& Krathwohl, 2001). Kemampuan kognitif dari level C3 (applying) sampai dengan C6 (creating) dapat dikatakan sebagai High Order Thinking Skill (HOTS) (Widodo \& Kadarwati, 2013). Kemampuan kognitif yang tinggi dapat membantu mahasiswa mendefinisikan ide, berargumen, memecahkan masalah, mengkonstruksi informasi atau data, beropini dan memahami situasi yang kompleks (Dinni, 2018).

Kemampuan kognitif mahasiswa dapat terlihat dari pertanyaan yang diajukan pada saat berdiskusi di kelas. Pertanyaan yang diajukan mahasiswa masih pada level memahami materi bioprospeksi saja dan belum pada tahap menganalisis atau mengevaluasi fenomena terkait materi bioprospeksi. Mahasiswa perlu dirangsang untuk meningkatkan kemampuan kognitifnya agar capaian pembelajaran dapat terpenuhi (Biggs, 2014; Dunlosky, Rawson, Marsh, Nathan, \& Willingham, 2013). Kemampuan kognitif ini dapat diukur melalui tes hasil belajar kognitif dan juga berpengaruh dalam keterampilan berpikir mahasiswa (Kurniawan, 2012; Nurcahya, 2016). Berdasarkan hasil analisis kebutuhan, dosen memiliki kendala pada saat mengajar Bioprospeksi yaitu kurangnya materi dan praktikum. Solusi yang dapat diterapkan adalah perlunya ditambahkan materi tentang energi yaitu energi terbarukan dan praktikum tentang penggunaan teknologi sains. Bioetanol merupakan energi terbarukan yang dapat menjadi materi tambahan untuk mahasiswa agar dapat meningkatkan kompetensi mahasiswa dalam bidang energi dan menunjang bioprospeksi itu sendiri. Sumber belajar pada matakuliah Bioprospeksi sangat beragam, tetapi masih belum ada bahan ajar berupa modul berdasarkan hasil penelitian yang dapat meningkatkan keterampilan berpikir kritis dan hasil belajar kognitif mahasiswa.

Hasil belajar kognitif dan keterampilan berpikir kritis mahasiswa masih rendah karena mahasiswa masih mengalami kesulitan dalam memahami materi Bioprospeksi. Mahasiswa kesulitan dalam memahami materi Bioprospeksi karena mahasiswa sulit mengaplikasikan konsep bioprospeksi, materi bioprospeksi abstrak dan kompleks, serta kurangnya sumber belajar yang relevan serta mudah diaplikasikan. Sumber belajar diharapkan relevan dan kontekstual agar dapat membantu mahasiswa memahami materi Bioprospeksi di berbagai bidang kehidupan.

Sumber belajar yang baik dapat membantu memenuhi capaian pembelajaran matakuliah (Hamid \& Jailani, 2016). Salah satu sumber belajar yang dapat digunakan mahasiswa dan dosen langsung dalam proses pembelajaran adalah bahan ajar . Hasil analisis menunjukkan bahwa mahasiswa memerlukan bahan ajar yang kontekstual, mudah dipahami dengan sumber yang terpercaya, praktis, dan mudah diakses. Modul memiliki karakteristik self-instructional, self-contained, stand alone, adaptif, user friendly dan konsistensi yang disusun secara sistematis dan menarik agar dapat mencapai kompetensi tertentu (Departemen Pendidikan Nasional, 2008). Bahan ajar berupa modul dapat membantu mahasiswa mandiri dengan materi kontekstual dan mudah diakses serta dapat meningkatkan hasil belajar kognitif dan keterampilan berpikir kritis mahasiswa (Noviyanti, 2017; Sari, 2017). 
Modul dapat dikembangkan berdasarkan hasil penelitian (Arianti, Sumarmin, \& Syukur, 2014; Fitriyati, Mufti, \& Lestari, 2015). Modul berdasarkan hasil penelitian dikembangkan berdasarkan pada teori pembelajaran, yaitu konstruktivisme. Pembelajaran ini lebih berpusat pada mahasiswa yang berarti mahasiswa terlibat aktif dalam proses pembelajaran itu sendiri (Tobias \& Duffy, 2009). Model pembelajaran konstruktivisme yang dapat mengembangkan berpikir kritis (Fakhriyah, 2014) dan hasil belajar adalah model pembelajaran Problem Based Learning (PBL) (Wulandari, Sjarkawi, \& Damris, 2011).

Model pembelajaran Problem Based Learning dapat menjadi dasar pengembangan modul (Alfiantara, Kusumo, \& Susilaningsih, 2016; Zulfadli, 2017) agar keterampilan berpikir kritis (Rokhim, Suparmi, \& Prayitno, 2016) dan hasil belajar kognitif mahasiswa dapat dikembangkan (Sulistiyani, 2017). Kegiatan pada pembelajaran $P B L$ adalah mengajukan masalah, mengajukan pertanyaan, dan memfasilitasi penyelidikan serta dialog antar mahasiswa (Arends, 2012). Modul berbasis Problem Based Learning berdasarkan hasil penelitian dikembangkan agar mahasiswa dapat belajar memecahkan masalah secara mandiri (Christiyoda, Widoretno, \& Karyanto, 2016) dengan materi kontekstual dari hasil penelitian (Arianti et al., 2014). Modul ini memungkinkan mahasiswa mengevaluasi sendiri hasil belajarnya sehingga mahasiswa lebih aktif belajar dengan dosen sebagai pembimbing pada saat pembelajaran berlangsung (Aisyah \& Purwoko, 2011).

\section{SIMPULAN}

Berdasarkan hasil dan pembahasan, maka dapat disimpulkan bahwa dibutuhkan bahan ajar berupa modul berdasarkan hasil penelitian sehingga diharapkan dapat meningkatkan keterampilan berpikir kritis dan hasil belajar kognitif mahasiswa. Modul yang dikembangkan berbasis model pembelajaran Problem Based Learning berkaitan dengan permasalahan yang terjadi di kehidupan sehari-hari. Pengembangan modul berbasis Problem Based Learning berdasarkan hasil penelitian dapat dikembangkan pada konsep dan materi matakuliah lain.

\section{DAFTAR RUJUKAN}

Aisyah, N., \& Purwoko. (2011). Peningkatan Hasil Belajar Mahasiswa Menggunakan Modul. Jurnal Ilmu Pendidikan, 17(5), 393-400.

Alfiantara, A., Kusumo, E., \& Susilaningsih, E. (2016). Pengembangan Modul Berorientasi Problem Based Learning Berbantuan Aplikasi Android. Jurnal Inovasi Pendidikan Kimia, 10(2), 1769-1777.

Anderson, L. W., \& Krathwohl, D. R. (2001). A Taxonomy for Learning, Teaching, and Assessing (Abridged). Boston: Allyn and Bacon.

Arends, R. I. (2012). Learning to Teach (9th ed.). New York: McGraw-Hill.

Arianti, P., Sumarmin, R., \& Syukur, U. (2014). Pengembangan Modul Bernuansa Hasil Riset pada Matakuliah Fisologi Reproduksi untuk Mahasiswa Biologi. Pendidikan Biologi Kolaboratif, 1(3), 27-34.

Basri, H. (2018). Kemampuan Kognitif dalam Meningkatkan Efektivitas Pembelajaran Ilmu Sosial bagi Siswa Sekolah Dasar. Jurnal Penelitian Pendidikan, 18(1), 1-9.

Biggs, J. B. (2014). What the Student Does: Teaching for Enhanced Learning University of New South Wales. Higher Education Research \& Development, 18(1), 57-75. https://doi.org/10.1080/07294360.2012.642839

Bušljeta, R. (2013). Effective Use of Teaching and Learning Resources. Czech-Polish Historical and Pedagogical Journal, 5(2), 55-69. https://doi.org/10.2478/cphpj-2013-0014

Christiyoda, S., Widoretno, S., \& Karyanto, P. (2016). Pengembangan Modul Berbasis Kemampuan Pemecahan Masalah pada Materi Sistem Ekskresi untuk Meningkatkan Berpikir Kritis. Jurnal Inkuiri, 5(1), 74-84.

Conley, D. T. (2007). Redefining College Readiness. Eugene.

Departemen Pendidikan Nasional. (2008). Panduan Penulisan Modul. (Direktorat Tenaga kependidikan \& Direktorat Jenderal Peningkatan Mutu Pendidik dan Tenaga Kependidikan, Eds.). Jakarta: Departemen Pendidikan Nasional.

Dinni, H. N. (2018). HOTS ( High Order Thinking Skills) dan Kaitannya dengan Kemampuan Literasi Matematika. In Prisma, Prosiding Seminar Nasional Matematika (Vol. 1, pp. 170-176). Semarang: Universitas Negeri Semarang.

Direktorat Jenderal Pendidikan Tinggi. (2014). Panduan Penyusunan Capaian Pembelajaran Lulusan Program Studi. Jakarta: Kementrian pendidikan dan Kebudayaan.

Dunlosky, J., Rawson, K. A., Marsh, E. J., Nathan, M. J., \& Willingham, D. T. (2013). Improving Students ' Learning With Effective Learning Techniques : Promising Directions From Cognitive and Educational Psychology. Psychological Science, 14(1), 4-58. https://doi.org/10.1177/1529100612453266

Embo, E. (2017). Pengaruh Penerapan Metode Pembelajaran Terhadap Motivasi Belajar Siswa Di Sekolah Menengah Kejuruan Negeri 4 Makassar. Universitas Negeri Makassar.

Fakhriyah, F. (2014). Penerapan Problem Based Learning dalam Upaya Mengembangkan Kemampuan Berpikir Kritis Mahasiswa. Jurnal Pendidikan IPA Indonesia, 3(1), 95-101.

Fitriyati, U., Mufti, N., \& Lestari, U. (2015). Pengembangan Modul Berbasis Riset pada Matakuliah Bioteknologi. Jurnal Pendidikan Sains, 3(3), 118-129.

Gates, D., Houtchens, B. C., Stodola, J., West, B., Dunlap, P., Fonoimoana, R., ... Prejean, A. (2012). Preparing 21st Century Students for a Global Society “An Educator's Guide to the Four Cs.” Washington DC: National Education Association. Greenhill, V., \& Petroff, S. (2010). 21ST Century Knowledge and Skills in Educator Preparation. Washington DC: Pearson. 
Hamid, A., \& Jailani, M. S. (2016). Pengembangan Sumber Belajar Berbasis Karakter Peserta Didik (Ikhtiar optimalisasi Proses Pembelajaran Pendidi- kan Agama Islam (PAI)). Nadwa: Jurnal Pendidikan Islam, 10(2), 175-192. DOI: http://dx.doi.org/10.21580/nw.2016.10.2.1284

Kementerian Pendidikan dan Kebudayaan. Undang-Undang Republik Indonesia Nomor 12 Tentang Pendidikan Tinggi (2012). Jakarta: Kemendikbud.

Khasanah, N. U. (2014). Pengaruh Metode Mengajar dan Media Pembelajaran terhadap Motivasi Belajar Siswa Kelas X Program Keahlian Administrasi Perkantoran SMK Negeri 1 Yogyakarta. Skripsi tidak diterbitkan. Universitas Negeri Yogyakarta, Yogyakarta.

Kopzhassarova, U., Akbayeva, G., Eskazinova, Z., Belgibayeva, G., \& Tazhikeyeva, A. (2016). Enhancement of Students' Independent Learning Through Their Critical Thinking Skills Development. International Journal of Environmental \& Science Education, 11(18), 11585-11592.

Kurniawan, A. H. (2012). Pengaruh Kemampuan Kognitif terhadap Kemampuan Psikomotorik Mata Pelajaran Produktif Alat Ukur Siswa Kelas X Jurusan Teknik Kendaraan Ringan di SMK Muhammadiyah Prambanan. Skripsi tidak diterbitkan Universitas Negeri Yogyakarta, Yogyakarta.

Masni, H. (2015). Strategi Meningkatkan Motivasi Belajar Mahasiswa. Dikdaya, 5(1), 34-45.

Nasution, M. K. (2017). Penggunaan Metode Pembelajaran Dalam Peningkatan Hasil Belajar Siswa. Studia Didaktika: Jurnal Ilmiah Bidang Pendidikan, 11(1), 9-16.

Novita, D., \& Afifah, D. S. N. (2014). Tingkatan Kemampuan Kognitif Siswa dalam Memecahkan Masalah Matematika Menggunakan Tes Superitem. Jurnal Pendidikan Matematika, 2(1), 19-33.

Noviyanti, R. (2017). Pengembangan Modul Berbasis PBL untuk Pembentukan Kemampuan Berpikir Kritis Siswa Kelas X SMA di Lampung Timur. Univeristas Lampung.

Nugraheni, A. (2012). Pengaruh Penggunaan Media Pembelajaran dan Gaya Belajar terhadap Prestasi Belajar Mahasiswa pada Matakuliah Konsep Kebidanan. Tesis tidak diterbitkan. Universitas Sebelas Maret, Surakarta.

Nurcahya, A. (2016). Perbedaan Hasil Belajar Kognitif Dan Kemampuan Berpikir Kritis Siswa dengan Pembelajaran Inkuiri Terbimbing dan Inkuiri Bebas Menggunakan “Talular” pada Mata Pelajaran Fisika di SMA Sugar Group. Universitas Lampung.

Persada, A. R. (2017). Peningkatan Hasil Belajar Matematika melalui Pengambangan Bahan Ajar Berbasis Website. EduMa, 6(1), 62-76.

Rokhim, A. R., Suparmi, A., \& Prayitno, B. A. (2016). Pengembangan Modul IPA Berbasis Problem Based Learning pada Materi Kalor dan Perpindahan untuk Meningkatkan Kemampuan Berpikir Kritis Siswa. In Prosiding Seminar Nasional Pendidikan Sains (pp. 68-75).

Rosenshine, B. (2012). Principles of Instruction: Research-based Strategies That All Teacher Should Know. American Educator, $12-20$.

Sarah, R., Iskandar, F., \& Andriyani, R. (2019). Pengembangan Bahan Ajar Trigonometri untuk Meningkatkan Kemampuan Berpikir Kritis Matematis Mahasiswa. In PRISMA, Prosiding Seminar Nasional Matematika. Vol. 2, pp. 759-763. Semarang: Universitas Negeri Semarang.

Sari, S. W. (2017). Pengembangan Modul Bioteknologi Berbasis Problem Based Learning (PBL) untuk Meningkatkan Hasil Belajar, Kemampuan Berpikir Kritis dan Sikap Siswa Kelas XII SMKN 2 Batu. Tesis tidak diterbitkan. Universitas Negeri Malang, Malang.

Sjakoer, N. A. A. (2019). Rencana Pembelajaran Semester Matakuliah Bioprospeksi. Malang.

Sulistiyani. (2017). Pengaruh Modul Pembelajaran Berbasis Problem Based Learning terhadap Hasil Belajar. Jurnal SAP, 2(2), $140-145$.

Supriadi. (2015). Pemanfaatan Sumber Belajar dalam Proses Pembelajaran. Lantanida Journal, 3(2).

Susiani, T. S., Salimi, M., \& Hidayah, R. (2018). Research Based Learning (RBL): How Improve Critical Thinking Skills? In SHS Web of Conferences (Vol. 42, pp. 1-6). EDP Sciences. https://doi.org/https://doi.org/10.1051/shsconf/20184200042

Tobias, S., \& Duffy, T. M. (2009). Constructivist Instruction: Success or Failure? (1st ed.). New York: Routledge.

Widodo, T., \& Kadarwati, S. (2013). High Order Thinking Berbasis Pemecahan Masalah untuk Meningkatkan Hasil Belajar Berorientasi Pembentukan Karakter Siswa. Cakrawala Pendidikan, 32(1), 161-171.

Wijoyo, A. (2018). Pengaruh Hasil Belajar Siswa Dengan Menggunakan Multi Media Pembelajaran Interaktif untuk Sekolah Menengah Pertama dan Sekolah Menengah Atas. Jurnal Informatika, 3(1), 46-55.

Wulandari, N., Sjarkawi, \& Damris, M. (2011). Pengaruh Problem Based Learning dan Kemampuan Berpikir Kritis terhadap Hasil Belajar Mahasiswa. Tekno-Pedagogi, 1(1), 14-24.

Zulfadli. (2017). Pengembangan Modul Biologi pada Materi Ekosistem Berbasis Problem Based Learning untuk Siswa. Jurnal Bionature, 17(1), 63-67. 